\title{
High Efficient Dye-Sensitized Solar Cells Based on Synthesized $\mathrm{SnO}_{2}$ Nanoparticles
}

\author{
W. M. N. M. B. Wanninayake, ${ }^{1,2}$ K. Premaratne, ${ }^{2,3}$ and R. M. G. Rajapakse ${ }^{2,4}$ \\ ${ }^{1}$ Department of Civil Engineering, University of Peradeniya, 20400 Peradeniya, Sri Lanka \\ ${ }^{2}$ Postgraduate Institute of Science, University of Peradeniya, 20400 Peradeniya, Sri Lanka \\ ${ }^{3}$ Department of Physics, University of Peradeniya, 20400 Peradeniya, Sri Lanka \\ ${ }^{4}$ Department of Chemistry, University of Peradeniya, 20400 Peradeniya, Sri Lanka
}

Correspondence should be addressed to W. M. N. M. B. Wanninayake; mihira.wanninayake@gmail.com

Received 13 October 2016; Accepted 21 November 2016

Academic Editor: Xiulin Fan

Copyright (c) 2016 W. M. N. M. B. Wanninayake et al. This is an open access article distributed under the Creative Commons Attribution License, which permits unrestricted use, distribution, and reproduction in any medium, provided the original work is properly cited.

\begin{abstract}
In this study, $\mathrm{SnO}_{2}$ semiconductor nanoparticles were synthesized for DSC applications via acid route using tin(ii) chloride as a starting material and hydrothermal method through the use of tin(iv) chloride. Powder X-ray diffraction studies confirmed the formation of the rutile phase of $\mathrm{SnO}_{2}$ with nanoranged particle sizes. A quasi-solid-state electrolyte was employed instead of a conventional liquid electrolyte in order to overcome the practical limitations such as electrolyte leakage, solvent evaporation, and sealing imperfections associated with liquid electrolytes. The gel electrolytes were prepared incorporating lithium iodide (LiI) and tetrapropylammonium iodide $\left(\operatorname{Pr}_{4} \mathrm{~N}^{+} \mathrm{I}^{-}\right)$salts, separately, into the mixture which contains polyacrylonitrile as a polymer, propylene carbonate and ethylene carbonate as plasticizers, iodide/triiodide as the redox couple, acetonitrile as the solvent, and 4-tertiary butylpyridine as an electrolyte additive. In order to overcome the recombination problem associated with the $\mathrm{SnO}_{2}$ due to its higher electron mobility, ultrathin layer of $\mathrm{CaCO}_{3}$ coating was used to cover the surface recombination sites of $\mathrm{SnO}_{2}$ nanoparticles. Maximum energy conversion efficiency of $5.04 \%$ is obtained for the device containing gel electrolyte incorporating $\mathrm{LiI}$ as the salt. For the same gel electrolyte, the ionic conductivity and the diffusion coefficient of the triiodide ions are $4.70 \times 10^{-3} \mathrm{~S} \mathrm{~cm}^{-1}$ and 4.31 $\times 10^{-7} \mathrm{~cm}^{2} \mathrm{~s}^{-1}$, respectively.
\end{abstract}

\section{Introduction}

Dye-sensitized solar cells (DSCs) have been investigated as the next generation of solar cells, due to their low production cost and easy fabrication procedures compared to those of conventional silicon solar cells. In 1991, Grätzel and his coworker invented a solar cell based on the ruthenium sensitizer adsorbed on nanoporous $\mathrm{TiO}_{2}$ semiconductor film [1]. However, the charge separation ability of $\mathrm{TiO}_{2}$-based DSC is suppressed by its low electron mobility $\left(<1 \mathrm{~cm}^{2} \mathrm{~V}^{-1} \mathrm{~s}^{-1}\right)$ resulting in a higher dark current [2]. Moreover, $\mathrm{TiO}_{2}$ shows a high photocatalytic effect and, as a result, sensitizer which is attached onto the nanoporous $\mathrm{TiO}_{2}$ network, prone to degrade rapidly. Therefore, in order to overcome these problems regarding $\mathrm{TiO}_{2}$-based DSCs, other high band gap semiconductors such as $\mathrm{ZnO}, \mathrm{SnO}_{2}$, and CdS were investigated as possible alternative semiconductor materials. Among these semiconductor materials, $\mathrm{SnO}_{2}$ shows relatively high electron mobility $\left(\sim 250 \mathrm{~cm}^{2} \mathrm{~V}^{-1} \mathrm{~s}^{-1}\right)$, high electron-hole separation ability, and high transport properties $[3,4]$. Other than its attractive properties, $\mathrm{SnO}_{2}$ nanoparticles can be synthesized using various techniques such as the hydrothermal method, sol-gel, and acid route. Here, we mainly aim to fabricate DSCs-based on the as-prepared $\mathrm{SnO}_{2}$ nanoparticles using acid route method and the hydrothermal method. Although $\mathrm{SnO}_{2}$ has promising electronic properties such as higher electron mobility, it shows inferior performance due to recombination of injected electrons with excited dye molecules and redox species of electrolyte. The recombination flux can be naturally divided into three elements as follows:

(1) Electron reaching recombination sites in the semiconductor surface. 
(2) Ions or hole reaching the surface from the electrolyte or hole-conductor side.

(3) Interfacial events.

Somehow, recombination occurs from the conduction band energy levels, $R_{r}^{\mathrm{cb}}$, and surface trap levels, $R_{r}^{\mathrm{ss}}$, can be expressed as follows:

$$
\begin{gathered}
R_{r}^{\mathrm{cb}}=R_{r, 0} \exp \left[\frac{-q V}{k_{B} T}\right] \\
R_{r}^{\mathrm{ss}}\left(E_{F n}\right)=R_{0}^{\prime} \exp \left[-\left[\frac{1}{2}+\alpha(T)\right] \frac{\left(E_{F n}-E_{\text {redox }}\right)}{k_{B} T}\right],
\end{gathered}
$$

where the terms have their usual meanings.

Generally, recombination rate is mainly affected by two factors: the position of the semiconductor energy level with respect to the redox levels and treatment of surface which intercept charge transfer from the semiconductor.

In this study, we focus on the blocking the semiconductor surface trap levels through the use of very thin layer of high band gap insulating material. Since the efficient electron tunnelling should be on the order of less than $10 \mathrm{~nm}$, study is focused on employing an ultrathin layer of coating layer on $\mathrm{SnO}_{2}$-based DSCs without greatly reducing the rate of photoinjection from excited dye molecules, that is, forward tunnelling of electrons. In order to verify the probability of forward tunnelling and back tunnelling of injected electrons, tunnelling transmission coefficient, $T$, equation was employed.

$$
T=\frac{16 E}{V_{o}}\left(1-\frac{E}{V_{0}}\right) \exp ^{-\left(\sqrt{2 m\left(V_{0}-E\right)} / \hbar\right) a}
$$

where $V_{0}$ is the barrier height, $m$ is the effective electron mass, and $a$ is the barrier width.

Photoexcited dye molecules cannot inject the electrons to the higher energy level of conduction band of the insulating material (band gap $6.00 \mathrm{eV}-9.00 \mathrm{eV}$ ) which is greater than $2.5 \mathrm{eV}$ with respect to the Lowest Unoccupied Molecular Orbital (LUMO) level of the dye molecules. The only possible way of reaching excited electron to conduction band of the semiconductor is by tunnelling. After the electrons tunnel into the conduction band, they relax towards the bottom of the conduction band acquiring lower energy state. These electrons will see the energy difference between the conduction band of the semiconductor and conduction band of the insulating material as a barrier height, $V_{0}(>4.3 \mathrm{eV})$. Then back tunnelling of electrons will be greatly reduced compared to forward tunnelling thus keeping the Fermi level of $\mathrm{SnO}_{2}$ in equilibrium.

Therefore, in order to suppress the recombination which occurs at the electrolyte/semiconductor interfaces of the $\mathrm{SnO}_{2}$ semiconductor network, $\mathrm{CaCO}_{3}$ coating layer is introduced to the system [5]. This $\mathrm{CaCO}_{3}$ layer would increase the photovoltaic performances of the composite $\mathrm{SnO}_{2} / \mathrm{CaCO}_{3}$ based DSCs as it acts as a barrier to the electrons which are in the conduction band of the $\mathrm{SnO}_{2}$ semiconductor network, by suppressing the back tunnelling of electrons.
Moreover, the conventional DSCs which consist of liquid electrolytes suffer from practical limitations, such as electrolyte leakage, solvent evaporation, and sealing imperfections. The use of gel electrolytes instead of liquid electrolytes would help to circumvent the above-mentioned drawbacks to a certain extent as gel electrolytes have promising properties, such as thermal stability, nonflammability, and nonvolatility. In this study the quasi-solid-state dye-sensitized solar cells (QSDSCs) were fabricated using as-prepared $\mathrm{SnO}_{2} / \mathrm{CaCO}_{3}$ composite working electrode and the gel electrolyte consists of propylene carbonate and ethylene carbonate as plasticizers, polyacrylonitrile as a polymer, acetonitrile as the solvent, 4tertiary butylpyridine as an electrolyte additive, and lithium iodide and tetrapropylammonium iodide as salts [6]. Additionally, this study was carried out with a metal-free organic dye, namely, indoline D358 dye, which has a high chelating ability $(\epsilon=13000)$.

In order to study the size effects of the nanoparticles used in DSC fabrication, $\mathrm{SnO}_{2}$ nanoparticles of different size were synthesized in our laboratory. Particle size could affect the device performance in two different ways. When the particle size is reduced to nanoscale, the effective surface area increases about 1000 times, hence increasing the dye adsorption by the same factor.

The effective surface area of a particle is increased when the particle size is decreased. For a given volume the relationship between the effective surface area $(S)$ and the particle size (d) can be expressed as follows [7]:

$$
S=\frac{k}{\rho d}
$$

Here $\rho$ is the density of the material and $k$ is a constant for the material of interest. The effective surface area of the material increases intensely for smaller particles resulting in higher dye adsorption.

This is a very positive contribution to enhance device performance. On the other hand, the lower particle size also leads to increased leaking of electrons from the semiconductor to recombine either with the redox species or with the oxidized dye molecules. It is explained as follows. Electron transport from the semiconductor network to FTO depends on these trapping and detrapping processes [8-10]. The following wave function describes the electrons in shallow traps [5]:

$$
U(r)=A e^{-r / a}
$$

where $r$ is the radial coordinate measured from the trapped site and $a$ is the parameter which has dimensions of length and it can be given as follows:

$$
a=\frac{\hbar}{\left(2 m^{*} E\right)^{1 / 2}},
$$

where $m^{*}$ is the effective electron mass. At room temperature, the parameter $a$ is $\sim 4 \mathrm{~nm}$ which is in the same order of magnitude as the crystallite radius of $\mathrm{SnO}_{2}$. That means electrons that are in the trapped levels could easily leak into the electrolyte. 
The electrons leakage and the amount of dye absorption are competing effects on the performance of DSCs. Therefore, we try to minimize the electron leakage though the use of $\mathrm{SnO}_{2} / \mathrm{CaCO}_{3}$ composite system by sacrificing the dye loading to some extent.

\section{Material and Methods}

\subsection{Preparation of $\mathrm{SnO}_{2}$ Nanoparticle}

Acid Route. First, tin(ii) chloride $\left(1.71 \times 10^{-2} \mathrm{~mol}\right.$, Aldrich, $98 \%)$ and citric acid $\left(4.16 \times 10^{-2} \mathrm{~mol}\right)$ were dissolved in deionized water until a saturated aqueous solution was formed. The resultant solution was heated slowly on a hot plate at $80^{\circ} \mathrm{C}$ to evaporate the solvent. Here, an amorphous glassy material was formed after the complete removal of water. Next, the amorphous material was calcined in a furnace in air for 30 minutes by varying temperature from $500^{\circ} \mathrm{C}$ to $750^{\circ} \mathrm{C}$.

Hydrothermal Method. The initial solution was prepared using the $\mathrm{SnCl}_{4} \cdot 2 \mathrm{H}_{2} \mathrm{O}$ (3.4 g, Aldrich, 98\%), conc. $\mathrm{HCl}$ $\left(8.00 \mathrm{~cm}^{3}\right.$, Aldrich, $\left.98 \%\right)$, and ethanol $\left(40.00 \mathrm{~cm}^{3}\right.$, Aldrich, $98 \%)$. This ratio gives the maximum yield as found by the preliminary study. The solution was poured into a Teflon flask and autoclaved at different temperatures from $180^{\circ} \mathrm{C}$ to $250^{\circ} \mathrm{C}$ for 15 hours. The above temperature range was selected since it was found that, at temperatures below $150^{\circ} \mathrm{C}$, the required material is not formed and temperatures between $150^{\circ} \mathrm{C}$ and $180^{\circ} \mathrm{C}$ do not give a considerable yield. Next, the greenish white precipitate was washed several times with deionized water (to remove excess ions in the medium), followed by ethanol. Then the precipitate was dried in a vacuum oven at $60^{\circ} \mathrm{C}$ for 24 hours.

2.2. Fabrication of Dye-Sensitized Solar Cells. As-prepared $\mathrm{SnO}_{2}(0.60 \mathrm{~g})$, acetic acid (Aldrich, 98\%, 10 drops), Triton X-100 (Aldrich, 98\%, 3 drops), ethanol (Aldrich, 98\%, $\left.40.0 \mathrm{~cm}^{3}\right)$, and $\mathrm{CaCO}_{3}(0.040 \mathrm{~g}$, Aldrich, $98 \%)$ were mixed thoroughly and the resulting $\mathrm{SnO}_{2} / \mathrm{CaCO}_{3}$ suspension was used to make devices after undergoing ultrasonic treatment. The $\mathrm{SnO}_{2} / \mathrm{CaCO}_{3}$ suspension was sprayed onto well-cleaned FTO glass $\left(10 \Omega \mathrm{cm}^{-2}\right)$ plates heated to $150^{\circ} \mathrm{C}$ on a hot plate. Then, the samples were sintered at $500^{\circ} \mathrm{C}$ for 30 minutes and were allowed to cool down to $80^{\circ} \mathrm{C}$. The samples were then immersed in an indoline D358 dye solution for 12 hours, and the dye coated- $\mathrm{SnO}_{2} / \mathrm{CaCO}_{3}$ films were rinsed with acetonitrile to remove any physically adsorbed dye molecules. Next, the electrolyte was sandwiched between the FTO $/ \mathrm{SnO}_{2} / \mathrm{CaCO}_{3}$ working electrode and a lightly platinized FTO counter electrode ( $\sim \Omega /$ sq, Aldrich) to assemble the solar cell device. Same procedure was followed to prepare the $\mathrm{SnO}_{2}$-based DSCs.

2.3. Preparation of Gel Polymer Electrolyte. In this experiment, $0.225 \mathrm{~g}$ of polyacrylonitrile (Aldrich), $0.525 \mathrm{~g}$ of ethylene carbonate (Aldrich, 98\%), $0.750 \mathrm{~g}$ of propylene carbonate (Aldrich, 99\%), and $0.020 \mathrm{~g}$ of iodine (Aldrich, 98\%) were mixed and stirred well in a magnetic stirrer for 12 hours.
$0.150 \mathrm{~g}$ of LiI (Aldrich, 99\%) (electrolyte Y) and $0.150 \mathrm{~g}$ of $\mathrm{Pr}_{4} \mathrm{~N}^{+} \mathrm{I}^{-}$(Aldrich, 98\%) (electrolyte $\mathbf{X}$ ) were used separately to prepare the gel electrolyte. Each time, the electrolytes were stirred at $80^{\circ} \mathrm{C}$ until the mixture turned into a clear, homogeneous, viscous gel. In each case, the gel electrolytes were subsequently pressed by sandwiching them between two clean glass plates to obtain a free-standing polymer film. They were subsequently dried in a vacuum desiccator overnight, at room temperature, to remove any absorbed moisture.

2.4. Preparation of Liquid Electrolyte. $1.55 \mathrm{~g}$ of dimethyl propyl imidazolium iodide, $0.65 \mathrm{~g}$ of 4-tertiary butylpyridine (Aldrich, 98\%), $0.13 \mathrm{~g}$ of LiI (Aldrich, 99\%), $0.12 \mathrm{~g}$ of iodine (Aldrich, 98\%), and $7.59 \mathrm{~g}$ of acetonitrile (Aldrich, 97\%) were mixed well in an environment of nitrogen and purged with nitrogen for 14 hours.

2.5. Characterization. In order to study the film morphology and the performance of the solar cell device, the following characteristic techniques were conducted. Crystallographic characterization of the $\mathrm{SnO}_{2}$ powder and composite $\mathrm{SnO}_{2}$ based films were done by means of powder X-ray diffraction (XRD) using a Siemens D5000 X-ray diffractometer with the $\mathrm{Cu} K \alpha$ radiation $(\lambda=0.1540562 \mathrm{~nm})$ at a scan rate of $1^{\circ} \mathrm{min}^{-1}$. The scanning electron microscopic (SEM) images were obtained using a Joel $6320 \mathrm{~F}$ scanning electron microscope. UV-Visible spectroscopy studies were carried out using a UV-spectrophotometer (UV-1800, SHIMADZU). The photovoltaic performance of the DSCs was measured by a solar simulator (PECCELL PEC-L01) with a source meter (Keithley 2400) at $25^{\circ} \mathrm{C}$ under AM $1.5\left(100 \mathrm{~mW} \mathrm{~cm}^{-2}\right)$ illumination. The total irradiated area of the DSCs was $0.25 \mathrm{~cm}^{2}$. In order to determine the particle size of the newly prepared $\mathrm{SnO}_{2}$ powder, a particle size analyzing experiment was carried out using a particle size analyzer Cilas Nano DS. The Electrochemical Impedance Spectroscopy (EIS) studies were carried out with a potentiostat (PGSTAT12) with a forward bias of $-0.58 \mathrm{~V}$ under dark conditions. The AC signal was $\pm 10 \mathrm{mV}$ in the frequency range of $0.01 \mathrm{~Hz}$ to $10 \mathrm{kHz}$.

\section{Results and Discussion}

First, newly prepared $\mathrm{SnO}_{2}$, using the acid route, was characterized and then moved onto the hydrothermal route which is rather of low cost. Initially, we attempted to find the better mediator for the synthesis of $\mathrm{SnO}_{2}$. Here, malonic acid, malic acid, and citric acid were employed to prepare $\mathrm{SnO}_{2}$ powder at $500^{\circ} \mathrm{C}$ and $600^{\circ} \mathrm{C}$. Then the resultant $\mathrm{SnO}_{2}$ powder was used to fabricate the DSCs. Results obtained are tabulated in Tables 1 and 2 .

Results in Tables 1 and 2 showed that the nanoparticles prepared with citric acid gave the best performance. This is possibly due to citric acid acting as the fuel itself giving out a large amount of heat during combustion. Combustion of the metal-acid complex is highly exothermic and releases a large amount of heat for quick conversion of the complex into its metal oxides. When citric acid is employed, there is no need to supply extra fuel into the system. The other possible reason 
TABLE 1: $I V$ parameters of the devices fabricated with as-prepared $\mathrm{SnO}_{2}$ synthesized at $500^{\circ} \mathrm{C}$.

\begin{tabular}{lcccc}
\hline Material & $J_{\mathrm{SC}}\left(\mathrm{mA} \mathrm{cm}^{-2}\right)$ & $V_{\mathrm{OC}}$ & FF & Efficiency \% \\
\hline Malic acid & 12.26 & 0.386 & 0.389 & 1.85 \\
Malonic acid & 9.38 & 0.373 & 0.374 & 1.30 \\
Citric acid & 13.75 & 0.420 & 0.458 & 2.65 \\
\hline
\end{tabular}

TABLE 2: $I V$ parameters of the devices fabricated with as-prepared $\mathrm{SnO}_{2}$ synthesized at $600^{\circ} \mathrm{C}$.

\begin{tabular}{lcccc}
\hline Material & $J_{\text {SC }}\left(\mathrm{mA} \mathrm{cm}^{-2}\right)$ & $V_{\mathrm{OC}}$ & FF & Efficiency \% \\
\hline Malic acid & 11.65 & 0.457 & 0.439 & 2.34 \\
Malonic acid & 11.44 & 0.403 & 0.406 & 1.87 \\
Citric acid & 14.95 & 0.422 & 0.457 & 2.88 \\
\hline
\end{tabular}

is the formation of bigger particles when we employ malic acid and malonic acid in place of citric acid. The possible complex of a divalent metal cation $\left(\mathrm{Sn}^{2+}\right)$ and citric acid can be depicted as shown in Figure 1 [11, 12].

If we consider the steric properties of malic and malonic acid, there is a higher possibility of aggregating more $\mathrm{Sn}^{2+}$ cations when malic and malonic acids are used as a mediator compared to the bulky structure of citric acid as shown in Figure 1. This hypothesis supports the argument that preparation of $\mathrm{SnO}_{2}$ nanoparticles using citric acid route is more efficient.

In order to find the average particle size of $\mathrm{SnO}_{2}$, initially we conducted the XRD studies and further confirmation was carried out using the particle size analyzer.

The XRD pattern of $\mathrm{SnO}_{2}$, sintered at $700^{\circ} \mathrm{C}$ for $30 \mathrm{~min}$ utes, is depicted in Figure 2. Samples were in polycrystalline form and they exhibited monoclinic crystal structure and their peak positions were identified and they are indexed corresponding to the (110), (101), (200), (111), (210) (211), (220), (002), (310), (112), (202), and (321) of the $\mathrm{SnO}_{2}$ (ICDD, 4-0477). The average particle size was estimated using the full width at half maximum (FWHM) of the XRD major peak by means of the Debye Scherrer formula.

Next, the particles were dispersed in deionized water by a magnetic stirrer and sonicated several times until a transparent colloidal solution is formed. Then the measurements were carried out using a particle size analyzer and the results obtained are shown in Figure 3.

According to the above plot, the sizes are much larger than expected as to the total diameter measured with the hydronium ions which were surrounded by $\mathrm{SnO}_{2}$ nanoparticles. As the isoelectric point is very low $(\sim 5 \mathrm{pH})$ in $\mathrm{SnO}_{2}$, it is easy to attach many hydronium layers on the $\mathrm{SnO}_{2}$ nanoparticles. It might be the reason for the higher hydrodynamic diameter compared to the particle size calculated by the XRD data as shown in Table 3. According to the results given in Table 3, particle sizes increase with the temperature. This might be due to the fact that the higher temperature will help to sinter with neighbour $\mathrm{SnO}_{2}$ nanoparticles thus making bigger particles.

Table 4 gives the variation of solar cell parameters with the particle size. Out of the six temperature values, $\mathrm{SnO}_{2}$
TABLE 3: Particle sizes calculated using XRD pattern and particle size analyzer.

\begin{tabular}{lcc}
\hline Temperature $\left({ }^{\circ} \mathrm{C}\right)$ & Crystalline size $(\mathrm{nm})$ & $\begin{array}{c}\text { Hydrodynamic } \\
\text { radius }(\mathrm{nm})\end{array}$ \\
\hline 500 & 25 & 51 \\
550 & 29 & 61 \\
600 & 33 & 63 \\
650 & 37 & 79 \\
700 & 45 & 81 \\
750 & 53 & 84 \\
\hline
\end{tabular}

TABLE 4: $I V$ parameters of the device fabricated with as-prepared $\mathrm{SnO}_{2}$ and with the Li-based gel electrolyte.

\begin{tabular}{lcccc}
\hline Temperature $\left({ }^{\circ} \mathrm{C}\right) J_{\text {SC }}\left(\mathrm{mA} \mathrm{cm}^{-2}\right)$ & $V_{\text {OC }}(\mathrm{V})$ & FF & Efficiency \% \\
\hline 500 & 13.75 & 0.420 & 0.458 & 2.65 \\
550 & 14.02 & 0.420 & 0.455 & 2.70 \\
600 & 14.95 & 0.422 & 0.457 & 2.88 \\
650 & 15.73 & 0.434 & 0.444 & 3.00 \\
700 & 12.26 & 0.386 & 0.389 & 1.85 \\
750 & 9.38 & 0.373 & 0.374 & 1.30 \\
\hline
\end{tabular}

nanoparticles synthesized at $650^{\circ} \mathrm{C}$ gave the best performance. According to the results shown in Table 3, $\mathrm{SnO}_{2}$ prepared in $650^{\circ} \mathrm{C}$ gave $37 \mathrm{~nm}$ which is the middle of the particle sizes in between $25 \mathrm{~nm}$ and $53 \mathrm{~nm}$. DSCs prepared in $550^{\circ} \mathrm{C}$ to $650^{\circ} \mathrm{C}$ showed similar $J_{\mathrm{SC}}$ values. This might be due to the fact that the particle size of about $30 \mathrm{~nm}$ is sensitive to both negative and positive effects occurring due to recombination and dye attachment. $V_{\mathrm{OC}}$ obtained for the DSCs fabricated at higher temperature is quite law. Even though we expected higher $V_{\mathrm{OC}}$ values from those DSCs due to reduction of the recombination as the bigger particle reduces recombination, it seems that bigger particle size greatly reduces the absorbed dye amount compared to the reduction of recombination.

In order to analyze the reasons for the variation of solar cell parameters with the particle size, our next attempt was to investigate the variation of the amount of dye loading with the particle size distribution as shown in Table 3. As previously discussed, samples were prepared in $1 \mathrm{~cm}^{2}$ area for desorption of the dye and the results obtained are plotted in Figure 4.

It is obvious that the highest dye amount can be observed for the particles with the lowest size. But the lowest particle size did not give the maximum efficiency. If it shows the highest dye loading, then it would be rich in electrons which are received from photoexcited dye molecules. The same fact will lead to increase in recombination as higher electron density increases the driving force of electrons.

But, again, lower particle size means that it is easier for the electrons to come out to the surface of $\mathrm{SnO}_{2}$ nanoparticles and recombine with triiodide or excited dye molecules as discussed in the Introduction. That would be the possible reason for lower performance of the lowest particles size. In order to confirm these explanations, EIS studies were 
<smiles>O=C(O)CC(O)C(=O)O</smiles>

Malic acid<smiles>CC(CC(=O)O)(CC(=O)O)C(=O)O</smiles>

Citric acid<smiles>O=C(O)CC(=O)O</smiles>

Malonic acid

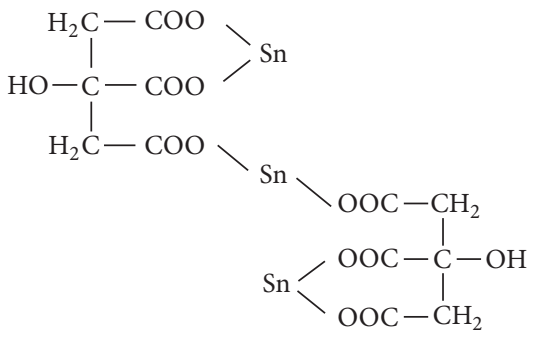

FIGURE 1: Chemical structures and possible formation mechanism of $\mathrm{SnO}_{2}$.

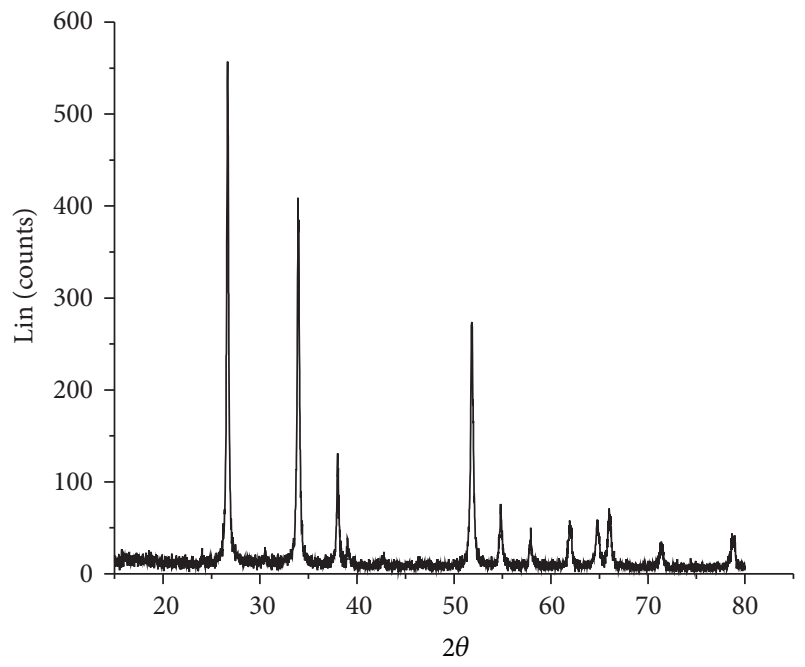

FIgURE 2: XRD pattern of $\mathrm{SnO}_{2}$.

TABLE 5: EIS parameters of the device fabricated with as-prepared $\mathrm{SnO}_{2}$ which is synthesized by varying the temperature.

\begin{tabular}{lccc}
\hline Temperature $\left({ }^{\circ} \mathrm{C}\right)$ & $R_{r}(\Omega)$ & $C_{\mu}(\mu \mathrm{F})$ & $\tau_{e}\left(\times 10^{-6} \mathrm{~s}\right)$ \\
\hline 500 & 12 & 2.5 & 30.0 \\
550 & 14 & 2.6 & 36.4 \\
600 & 15 & 2.7 & 40.5 \\
650 & 25 & 2.7 & 67.5 \\
700 & 17 & 2.5 & 42.5 \\
750 & 13 & 2.4 & 31.2 \\
\hline
\end{tabular}

conducted and calculated effective diffusion length together with the electron lifetime is given in Table 5.

The equivalent circuit was used to obtain the resistance and capacitance values which are presented in Table 5 . Smaller observed $R_{r}$ value means that the conduction band electrons could easily recombine with the triiodide ions in the electrolyte, thus lowering $V_{\mathrm{OC}}$. $R_{r}$ values obtained for the device fabricated with particles synthesized at $500^{\circ} \mathrm{C}$ are much smaller compared to the device fabricated with particles synthesized at $650^{\circ} \mathrm{C}$. The electron recombination occurring in particles sensitized at $500^{\circ} \mathrm{C}$ and $750^{\circ} \mathrm{C}$ could be much faster compared to the particles sensitized at $650^{\circ} \mathrm{C}$. This can be further confirmed by using the electron lifetimes

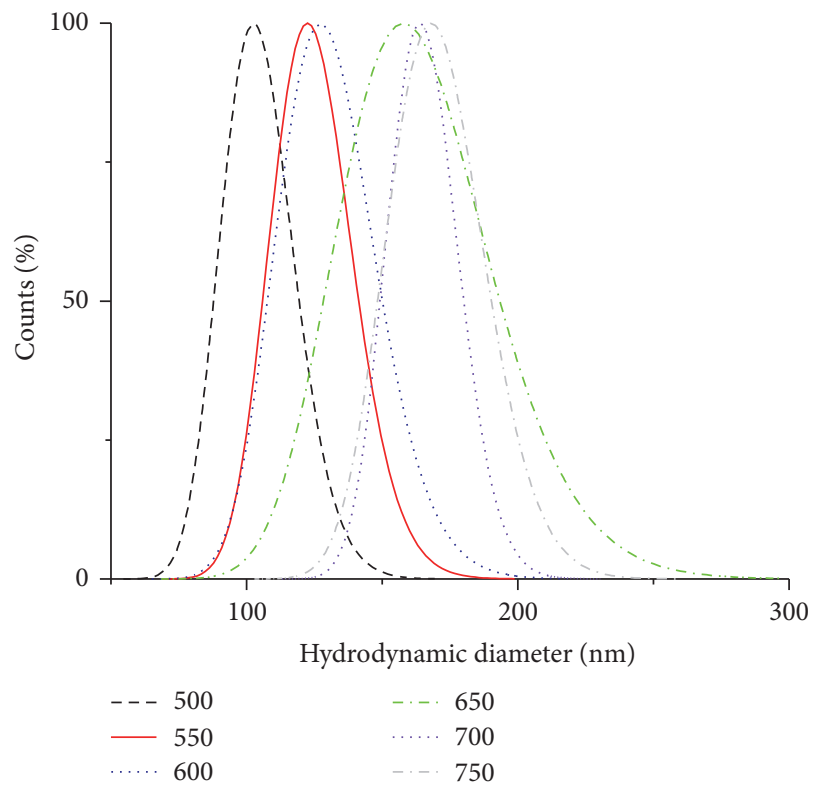

FIGURE 3: Particle size distribution with the calcination temperature.

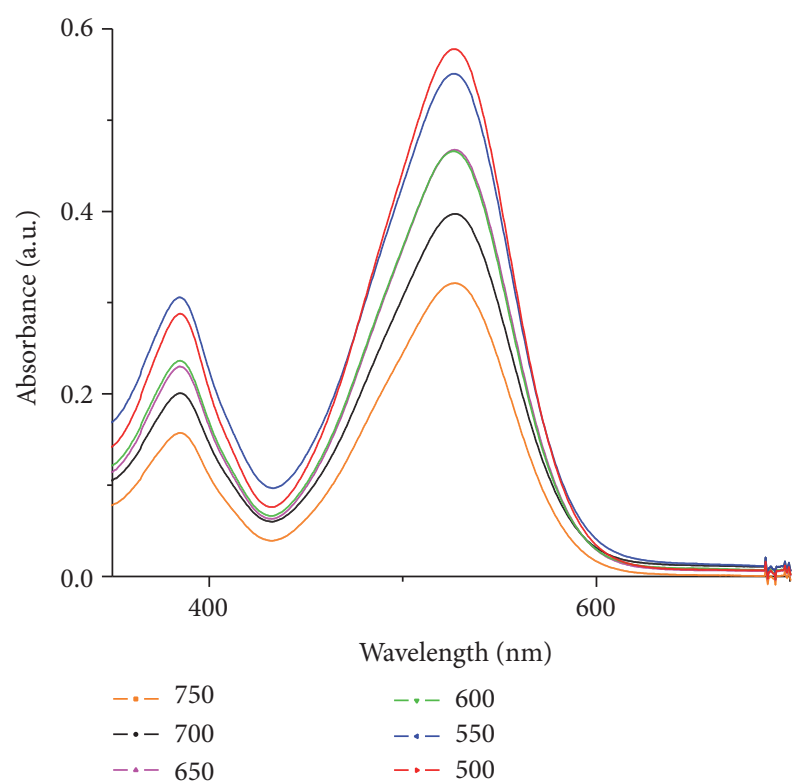

FIgURE 4: Variation of amount of dye with the particle size of $\mathrm{SnO}_{2}$. 
TABLE 6: Variation of particle size with the autoclave temperatures.

\begin{tabular}{lc}
\hline Temperature $\left({ }^{\circ} \mathrm{C}\right)$ & Average particle size $(\mathrm{nm})$ \\
\hline 150 & 19 \\
180 & 23 \\
190 & 25 \\
200 & 27 \\
220 & 33 \\
240 & 37 \\
250 & 43 \\
\hline
\end{tabular}

TABLE 7: IV parameters of devices fabricated with as-prepared $\mathrm{SnO}_{2}$ and with the liquid electrolyte.

\begin{tabular}{lcccc}
\hline $\begin{array}{l}\text { Temperature } \\
\left({ }^{\circ} \mathrm{C}\right)\end{array}$ & $\begin{array}{c}J_{\mathrm{SC}} \\
\left(\mathrm{mA} \mathrm{cm}^{-2}\right)\end{array}$ & $V_{\mathrm{OC}}(\mathrm{V})$ & FF & Efficiency \% \\
\hline 150 & 12.26 & 0.386 & 0.489 & 2.31 \\
180 & 14.60 & 0.430 & 0.490 & 3.51 \\
190 & 18.98 & 0.496 & 0.503 & 4.48 \\
200 & 19.30 & 0.490 & 0.530 & 5.00 \\
220 & 17.55 & 0.466 & 0.515 & 4.22 \\
240 & 13.10 & 0.511 & 0.585 & 3.90 \\
250 & 11.28 & 0.537 & 0.553 & 3.34 \\
\hline
\end{tabular}

which were obtained from EIS by fitting the experimental data through an appropriate equivalent circuit. Device fabricated using $\mathrm{SnO}_{2}$ nanopowder synthesized at $650^{\circ} \mathrm{C}$ showed $125 \%$ of increase when compared to device made by employing nanoparticles synthesized at $500^{\circ} \mathrm{C}$.

The next attempt was to systemize the $\mathrm{SnO}_{2}$ nanoparticles using the hydrothermal method. As discussed earlier, this is a very simple and cheap method. $\mathrm{SnCl}_{4}, \mathrm{HCl}$, and ammonia were used in a precursor solution and it was autoclaved under relatively low temperature. The resultant greenish powder was separated and the precipitate was washed several times with deionized water and vacuum dried for 12 hours. Thus the powder samples obtained underwent XRD characterization and results are tabulated in Table 6. Samples were also used to fabricate DSCs and results are given in Table 7. Table 6 also shows the same trend of Table 3 . This might be due to the same reason described in earlier section.

In the hydrothermal method, formation of $\mathrm{SnO}_{2}$ nanoparticles can be explained as follows. The behavior of $\mathrm{NH}_{3}$ may correlate to a process named molecule recognition that could have taken place at the inorganic/organic interface due to charge and stereochemistry complementarity $[13,14]$. In an aqueous medium, $\mathrm{NH}_{3}$ would ionize completely and result in a tetrahedral orientation with the electron lone-pair and it would be incorporated with $\mathrm{Sn}^{4+}$ cation as depicted on the left side of Figure 5. A possible mechanism for the tinplating process is forming micelles that contained many tin cations $\left(\mathrm{H}_{3} \mathrm{~N}-\mathrm{Sn}^{4+}\right.$ complexes) on the surface. The micelles act as nucleating points for the growth of $\mathrm{SnO}_{2}$ crystals. During the hydrothermal process, $\mathrm{H}_{3} \mathrm{~N}-\mathrm{SnO}_{2}$ complexes could be formed. And they coalesce to form a large particle. Since the crystallization process was under the

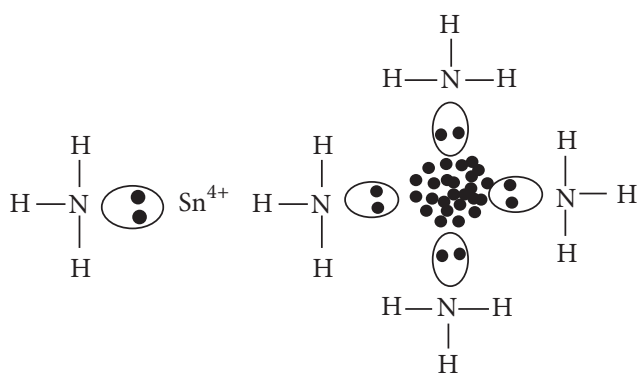

FIGURE 5: Formation of nucleation and crystal growth mechanism.

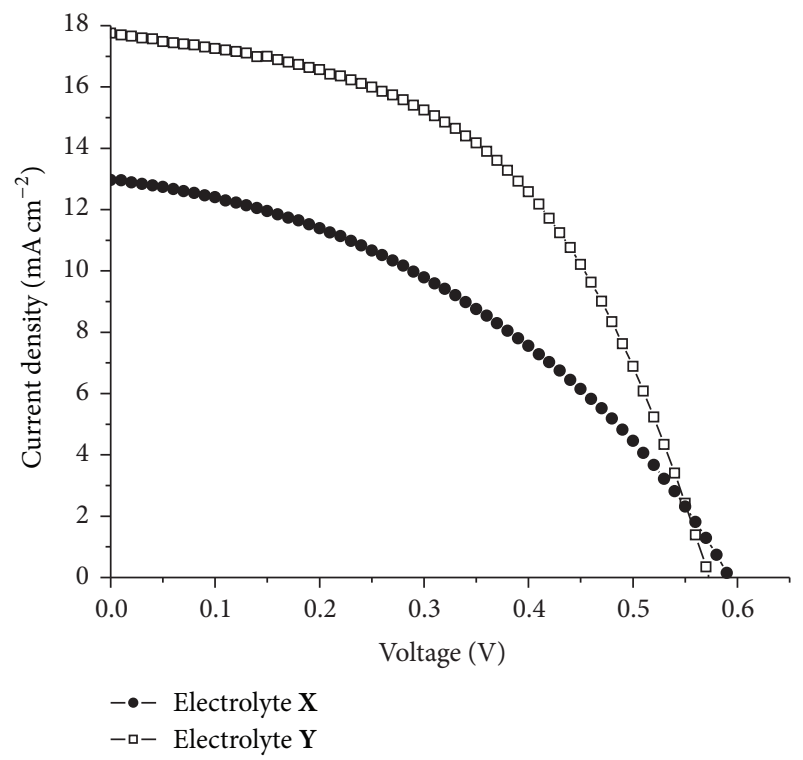

Figure 6: $I-V$ curves obtained for $\mathrm{SnO}_{2} / \mathrm{CaCO}_{3}$ DSCs fabricated with electrolytes $X$ and $Y$.

critical control of $\mathrm{NH}_{3}$, resulting particles were invariably spherical $[15,16]$. Generally, coagulation of the submicron sized particles only occurred in the sample prepared at higher precursor concentrations as $\mathrm{NH}_{3}$ molecules were unable to fully envelop the particles while crystal growth took place. Therefore, low precursor concentrations were used here in order to control the aggregation of particles.

Cells prepared with only $\mathrm{SnO}_{2}$ showed relatively low performance due to lower $V_{\mathrm{OC}}$ and fill factor as shown in Table 8. In order to enhance $V_{\mathrm{OC}}$ of the solar cell devices, $\mathrm{CaCO}_{3}$ coated $\mathrm{SnO}_{2}$ dye-sensitized solar cells were employed. As one of the prime aims of this study is to find the practical suitability of a gel polymer electrolyte in DSCs, here we employed a gel polymer electrolyte. As expected, $V_{\mathrm{OC}}$ is enhanced while sacrificing the short-circuit current density to a certain extent as depicted in Figure 6.

In order to examine the composite nature of the fabricated films, XRD studies were conducted. Figure 7 shows XRD spectra obtained for all three composite materials and the composition is verified using standard ICCD data. The planes responsible for these diffractions due to each compound are shown within the XRD spectra. 
TABLE 8: $I V$ parameters of the devices fabricated using different synthesization techniques.

\begin{tabular}{lcccccc}
\hline Method & Temperature $\left({ }^{\circ} \mathrm{C}\right)$ & Crystalline size $(\mathrm{nm})$ & $J_{\mathrm{SC}}\left(\mathrm{mA} \mathrm{cm}^{-2}\right)$ & $V_{\mathrm{OC}}(\mathrm{V})$ & FF & Efficiency $\%$ \\
\hline Hydrothermal & 200 & 27 & 14.40 & 0.455 & 0.494 & 3.24 \\
Acid route & 650 & 37 & 11.65 & 0.457 & 0.439 & 2.34 \\
\hline
\end{tabular}

TABLE 9: Photovoltaic values of $\mathrm{SnO}_{2} / \mathrm{CaCO}_{3}$ DSCs fabricated using electrolytes $X$ and $Y$.

\begin{tabular}{lcccc}
\hline Electrolyte & $\begin{array}{c}J_{\mathrm{SC}} \\
\left(\mathrm{mA} \mathrm{cm}^{-2}\right)\end{array}$ & $V_{\mathrm{OC}}(\mathrm{V})$ & Fill factor & Efficiency \% \\
\hline$X$ & 13.0 & 0.592 & 0.487 & 3.75 \\
$Y$ & 17.7 & 0.573 & 0.496 & 5.04 \\
\hline
\end{tabular}

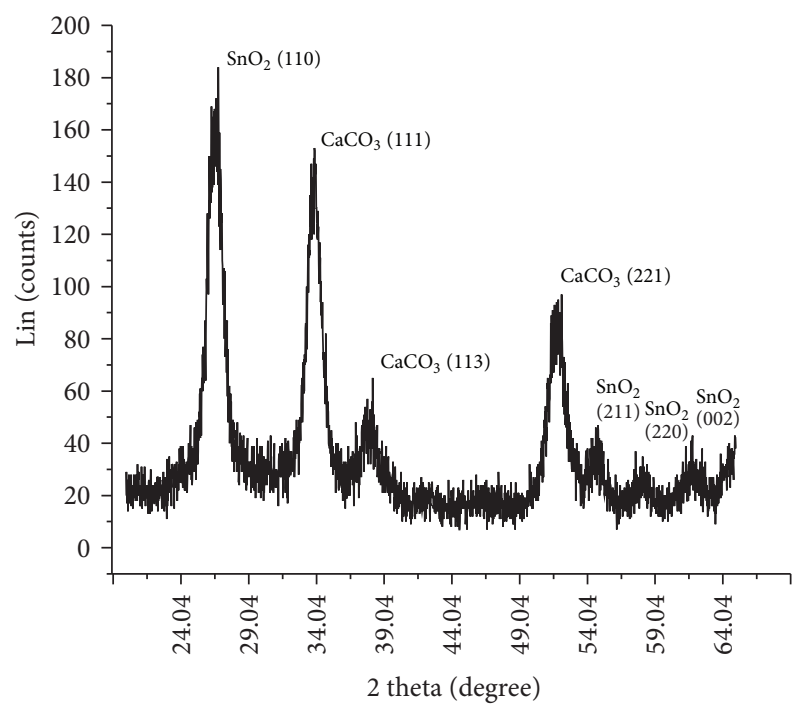

FIGURE 7: XRD patterns of the composite systems of $\mathrm{SnO}_{2} / \mathrm{CaCO}_{3}$.

The scanning electron microscopic (SEM) graphs were examined in order to study the film morphology. According to Figure 8, they show interconnected porous structures in composite systems which are favorable for enhanced dye adsorption due to increase in the surface area and for sufficient electrolyte penetration due to nanoporous structures.

Table 9 shows the performance of the solar cell devices fabricated using hydrothermal method. According to the results shown in Tables 8 and $9, \mathrm{CaCO}_{3}$ coated $\mathrm{SnO}_{2}$ device shows $55 \%$ increase of efficiency compared to the bare $\mathrm{SnO}_{2}$ based device. It is considerable amount increase. This can be considered to be due to reduction of the recombination as coating layer suppresses the back tunnelling of the injected electron. This phenomenon will be proved by the $30 \%$ increase of $V_{\mathrm{OC}}$ due to $\mathrm{CaCO}_{3}$ coating on top of the $\mathrm{SnO}_{2}$ nanoparticles. As shown in Table 9, the best $I-V$ performances were obtained for the electrolyte $Y$ due to the higher short-circuit current density compared with that of $X$. This might be due to the lowering of conduction band edges by shifting towards a more positive potential via adsorbing $\mathrm{Li}^{+}$ ions onto the semiconductor surface. Therefore, a favorable energy gap will be formed for the electron injection from the

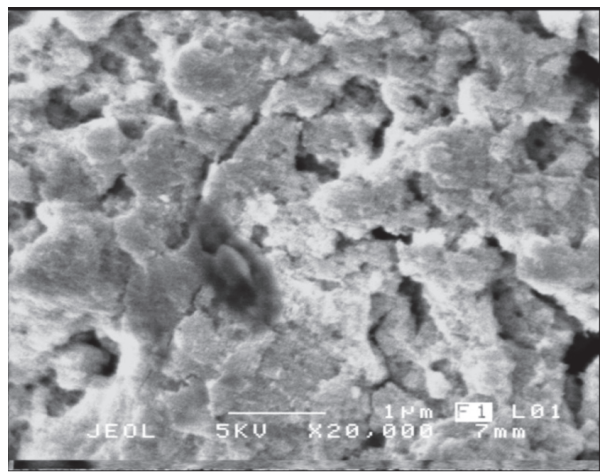

(a)

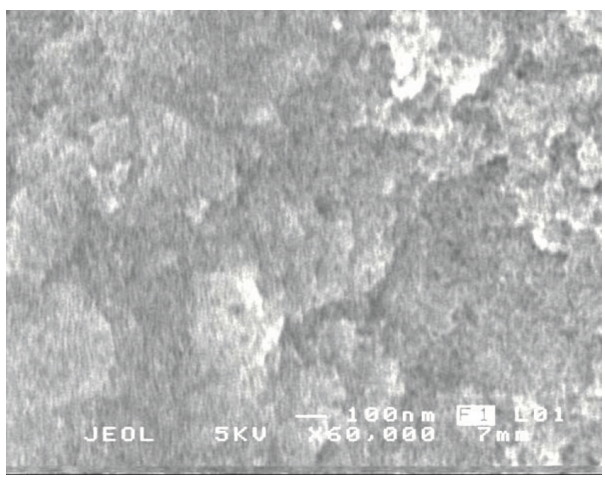

(b)

Figure 8: SEM images of $\mathrm{SnO}_{2}$ coated with (a) $\mathrm{CaCO}_{3}$ and (b) $\mathrm{SnO}_{2}$.

sensitizer molecules to the conduction band of the $\mathrm{SnO}_{2}$ and thereby $J_{\mathrm{SC}}$ of the device is increased while lowering $V_{\mathrm{OC}}$ of the device compared to the electrolyte $X$ based DSCs.

Another possibility for the higher $J_{S C}$ value of the device fabricated with the electrolyte $Y$ is the formation of a more amorphous polymer network which helps transport triiodide ions. Coordination interaction in between $\mathrm{CN}$ groups of PAN and $\mathrm{Li}^{+}$ions will help formation of cross-linking site thus increasing amorphousness of gel polymer electrolyte [6].

\section{Conclusion}

The $\mathrm{SnO}_{2}$ nanoparticles were synthesized using tin(iv) chloride and tin(ii) chloride as the starting materials. The best particle size for DSCs applications is of about $30 \mathrm{~nm}$. Even though $\mathrm{SnO}_{2}$-based DSCs show higher current density they show a low open circuit voltage. One possible method of improving $V_{\mathrm{OC}}$ is the introduction of $\mathrm{CaCO}_{3}$ coating layer sacrificing the current density to a certain extent. Comparably the best photovoltaic performances were obtained with the gel electrolyte consisting of LiI for the composite 
$\mathrm{SnO}_{2} / \mathrm{CaCO}_{3}$ system. The highest values of $J_{\mathrm{SC}}, V_{\mathrm{OC}}$, fill factor, energy conversion efficiency, ionic conductivity, and diffusion coefficient of triiodide ions with LiI-based gel electrolyte, were $17.7 \mathrm{~mA} \mathrm{~cm}^{-2}, 0.573 \mathrm{~V}, 0.496,5.04 \%, 4.70 \mathrm{~S} \mathrm{~cm}^{-1}$, and $4.31 \times 10^{-7} \mathrm{~cm}^{2} \mathrm{~s}^{-1}$, respectively. These results could be attributed to the higher degree of amorphous nature of the gel electrolyte, due to formation of cross-linking sites with $\mathrm{Li}^{+}$ ions and due to the suppression of the recombination by TBP and the $\mathrm{CaCO}_{3}$ coating layer.

\section{Competing Interests}

The authors declare that there is no conflict of interests regarding the publication of this paper.

\section{Acknowledgments}

Financial support from the National Research Council, Sri Lanka, through research Grant no. NRC 08-17 is gratefully acknowledged.

\section{References}

[1] B. O’Regan and M. Grätzel, "A low-cost, high-efficiency solar cell based on dye-sensitized colloidal $\mathrm{TiO}_{2}$ films," Nature, vol. 353, no. 6346, pp. 737-740, 1991.

[2] K. Premaratne, G. R. A. Kumara, R. M. G. Rajapakse, and M. L. Karunarathne, "Highly efficient, optically semi-transparent, ZnO-based dye-sensitized solar cells with Indoline D-358 as the dye," Journal of Photochemistry and Photobiology A: Chemistry, vol. 229, no. 1, pp. 29-32, 2012.

[3] Z. M. Jarzebski, "Physical properties of $\mathrm{SnO}_{2}$ materials," Journal of the Electrochemical Society, vol. 123, no. 9, pp. 299C-310C, 1976.

[4] H. Wang, B. Li, J. Gao et al., " $\mathrm{SnO}_{2}$ hollow nanospheres enclosed by single crystalline nanoparticles for highly efficient dyesensitized solar cells," CrystEngComm, vol. 14, no. 16, pp. 51775181, 2012.

[5] W. M. N. M. B. Wanninayake, K. Premaratne, G. R. A. Kumara, and R. M. G. Rajapakse, "A study of the efficiency enhancement of the gel electrolyte-based $\mathrm{SnO}_{2}$ dye-sensitized solar cells through the use of thin insulating layers," Electrochimica Acta, vol. 210, pp. 138-146, 2016.

[6] W. M. N. M. B. Wanninayake, K. Premaratne, G. R. A. Kumara, and R. M. G. Rajapakse, "Use of lithium iodide and tetrapropylammonium iodide in gel electrolytes for improved performance of quasi-solid-state dye-sensitized solar cells: recording an efficiency of 6.40\%," Electrochimica Acta, vol. 191, pp. 10371043, 2016.

[7] I. E. Dubois, S. Holgersson, and S. Allard, "Correlation between particle size and surface area for chlorite and K-feldspar," WaterRock Interact, vol. 1, p. 720, 2010.

[8] K. Tennakone, G. R. R. A. Kumara, I. R. M. Kottegoda, and V. P. S. Perera, "An efficient dye-sensitized photoelectrochemical solar cell made from oxides of tin and zinc," Chemical Communications, pp. 15-16, 1999.

[9] K. Tennakone, V. P. S. Perera, I. R. M. Kottegoda, and G. R. R. A. Kumara, "Dye-sensitized solid state photovoltaic cell based on composite zinc oxide/tin (IV) oxide films," Journal of Physics D: Applied Physics, vol. 32, no. 4, pp. 374-379, 1999.
[10] S.-S. Kim, J.-H. Yum, and Y.-E. J. Sung, "Flexible dye-sensitized solar cells using $\mathrm{ZnO}$ coated $\mathrm{TiO}_{2}$ nanoparticles," Journal of Photochemistry and Photobiology A: Chemistry, vol. 171, no. 3, pp. 269-273, 2005.

[11] M. S. G. Baythoun and F. R. Sale, "Production of strontiumsubstituted lanthanum manganite perovskite powder by the amorphous citrate process," Journal of Materials Science, vol. 17, no. 9, pp. 2757-2769, 1982.

[12] M. Bhagwat, P. Shah, and V. Ramaswamy, "Synthesis of nanocrystalline $\mathrm{SnO} 2$ powder by amorphous citrate route," Materials Letters, vol. 57, no. 9-10, pp. 1604-1611, 2003.

[13] D. H. Gray, S. Hu, E. Juuang, and D. L. Gin, "Highly ordered polymer-inorganic nanocomposites via monomer self assembly: in situ condensation approach," Advanced Materials, vol. 9, no. 9, pp. 731-736, 1997.

[14] D. Walsh, J. L. Kingston, B. R. Heywood, and S. Mann, "Influence of monosaccharides and related molecules on the morphology of hydroxyapatite," Journal of Crystal Growth, vol. 133, no. 1-2, pp. 1-12, 1993.

[15] Y. Wang, S. Zhang, K. Wei, N. Zhao, J. Chen, and X. Wang, "Hydrothermal synthesis of hydroxyapatite nanopowders using cationic surfactant as a template," Materials Letters, vol. 60, no. 12, pp. 1484-1487, 2006.

[16] H. Lim, A. Kassim, N. Huang et al., "Fabrication and characterization of $1 \mathrm{D}$ brushite nanomaterials via sucrose ester reverse microemulsion," Ceramics International, vol. 35, no. 7, pp. 28912897, 2009. 

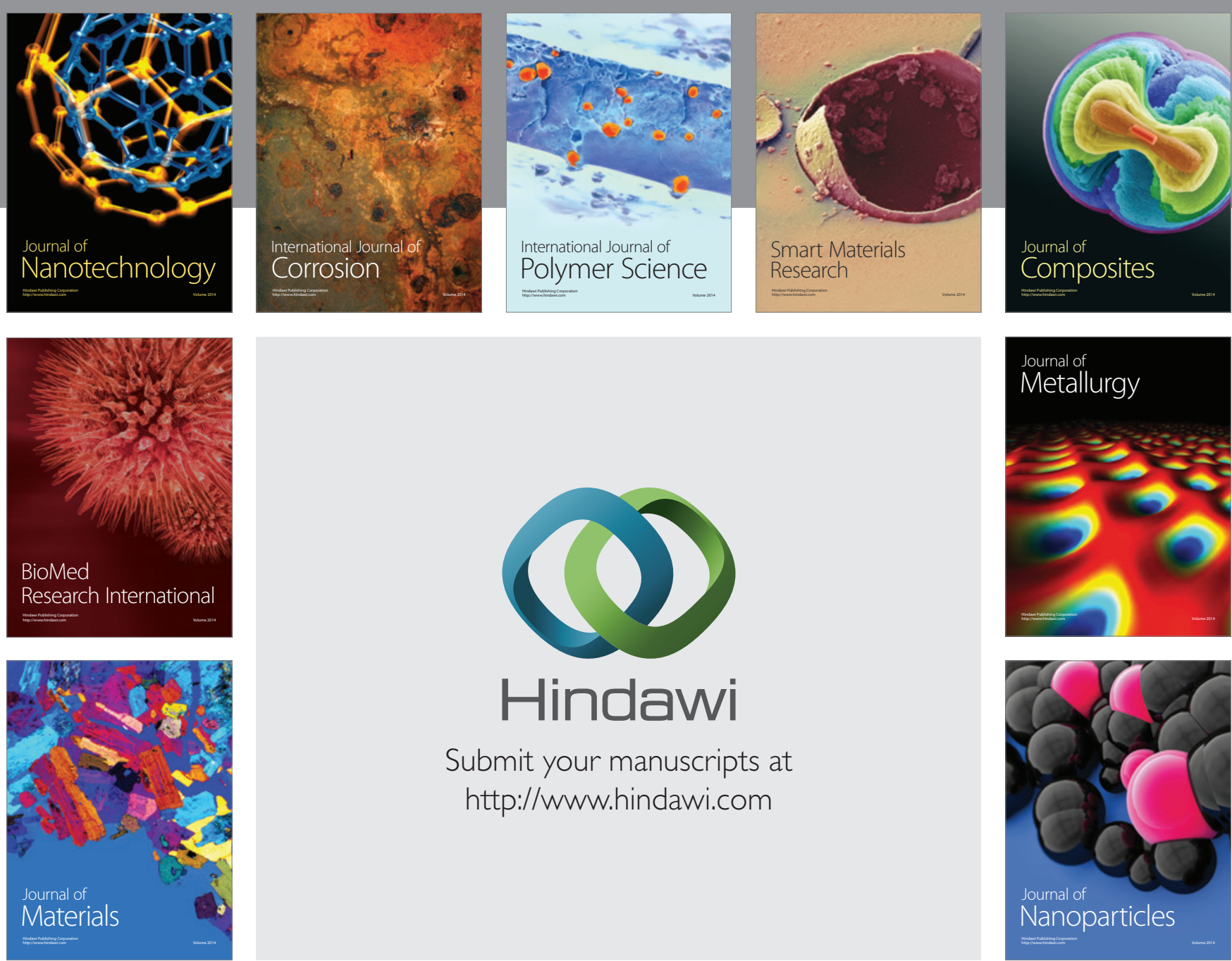

\section{Hindawi}

Submit your manuscripts at

http://www.hindawi.com

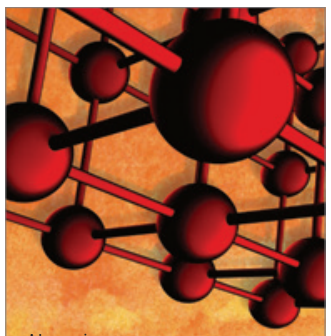

Materials Science and Engineering
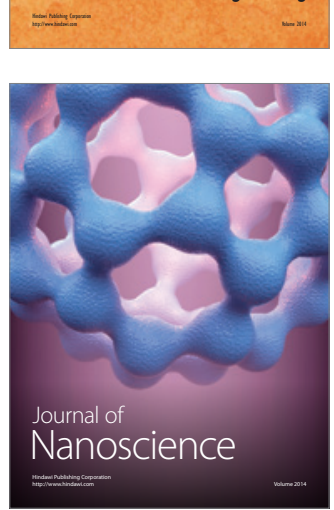
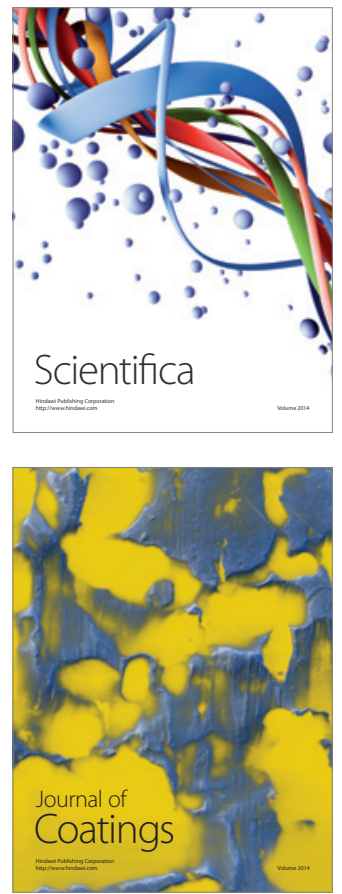
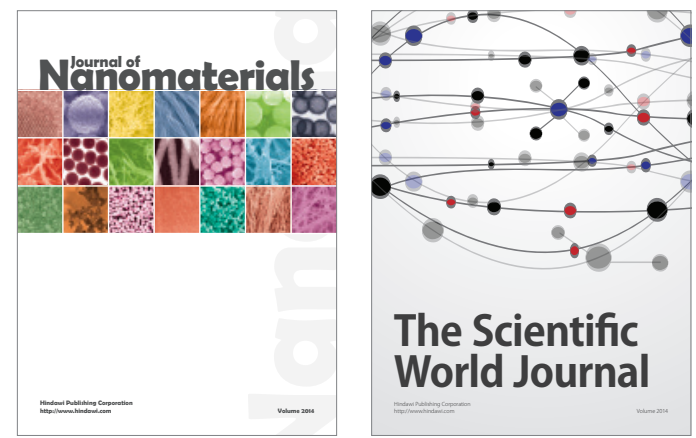

The Scientific World Journal
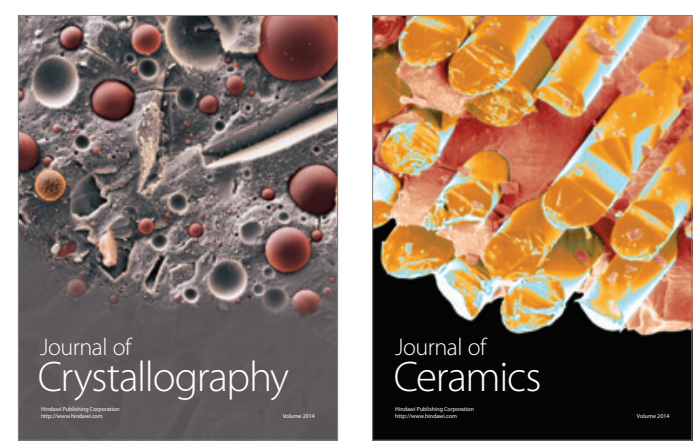
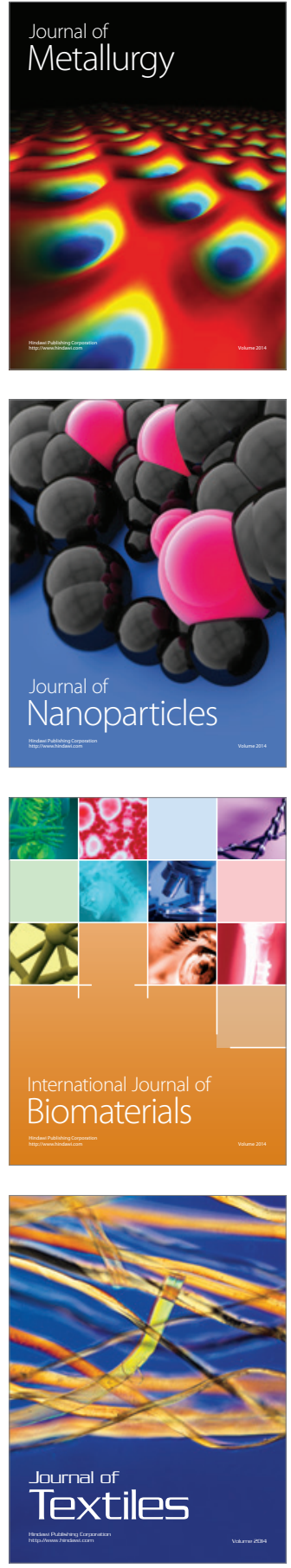